\title{
Limitations to self-management of adjustable compression wraps in the elderly : results of a prospective cohort study
}

\author{
Balet $\mathbf{F}^{1}$, * Benigni $\mathbf{J P}^{2}$, Uhl $\mathrm{JF}^{3}$, Chahim $\mathbf{M}^{4}$, Filori $\mathbf{P}^{5}$
}

${ }^{1}$ Private nurse, Pélissanne, 13330, France

${ }^{2}$ Pedagogical Support Office, Faculty of Medicine Pitié-Salpétrière, Sorbonne University, France,

${ }^{3}$ Paris Descartes University, Paris, France; Urdia Research Unit, Paris Descartes University, Paris, France.

${ }^{4}$ Geriatrician, Paris, France, Urdia Research Unit, Paris Descartes University, Paris, France.

${ }^{5}$ Private physiotherapist, Marseille, France.

\begin{abstract}
:
BACKGROUND : Adjustable compression wraps are used for treating lymphedema and chronic venous insufficiency. These diseases often affect elderly patients with associated pathologies or other limiting factors. These can prevent the self-application of the device by patients on themselves. A better understanding of these factors or the associated pathologies in the elderly is important before prescribing or not prescribing a wrap.

METHODS : The objective of this prospective cohort study was to determine the main factors that prevent the self-application of the device (Circaid Juxtalite ${ }^{R}$ ) to the lower limb in the elderly. A private nurse selected the first 30 retired subjects over 65 years of age seen at home for routine nursing care. After a demonstration, she asked them to put on the wrap in order to reach a pressure of $40 \mathrm{mmHg}$ in the calf (point B1). She recorded the pressures as the subjects applied the wrap twice in a row. The next day, the subject repeated the application of the wrap twice. We considered that an average pressure of more than $30 \mathrm{mmHg}$ is recommended to treat venous edema or ulceration.

RESULTS : $30 \%$ of the subjects put on the wrap by themselves with an average pressure of at least $30 \mathrm{mmHg}$. Age is not a limiting factor. Obesity, gripping difficulties, cognitive impairment and low social status seem to be factors limiting the daily self-management of an adjustable compression wrap in the elderly.

CONCLUSIONS : .

The self-management of adjustable compression wraps in the elderly person encounters obstacles that need to be known. The investigation has revealed that obesity, gripping difficulties, cognitive impairment and low social status are limiting factors. Age was not shown to be a limiting obstacle.
\end{abstract}

\section{KEYWORDS :}

Adjustable compression wraps - Aging - Compression pressure - Self-application - Lower limbs.

*Corresponding author: Benigni Jean-Patrick, 15 avenue du Général de Gaulle, Saint-Mandé, F94160 benigni.jp@orange.fr

\section{CONFLICT OF INTEREST AND FUNDING :}

The authors have no conflict of interest to declare with this study. They did not receive fees from any manufacturers. 


\section{BACKGROUND :}

Adjustable compression wraps are compressive devices existing since more than 20 years in the USA. They are made with short stretch material secured with a Velcro ${ }^{R}$. Several brands are available on the market. Clinical trials proving their effectiveness or their interest remain few to date. Although bandages $(1,2)$ are the basic treatment for venous leg ulcers, a few trials have proven the effectiveness of adjustable compression wraps in the healing of ulcers $(3,4)$. The superiority of adjustable wraps in the reduction of a venous edema compared to a short stretch bandage has been the subject of two publications $(5,6)$. In the initial and maintenance treatment of the upper limb lymphoedema, several publications have proved the effectiveness (7-9). In the other hand, an Austrian team compared the comfort of wraps, short stretch bandages and multi-component bandages (10). The wraps appear to be the most comfortable devices for decongestion therapy (11). H. Partsch and G. Mosti evaluated the effective interface pressures in patients or healthy subjects after self-application of a wrap $(12,13)$. After demonstration, effective pressures are easily obtained by subjects and are reproducible over time.

These devices appear to have all the qualities for wide use in the compressive treatment of lymphedema and chronic venous insufficiency.

In one hand, according to the last consensus conference (14) an average pressure of at least 30 $\mathrm{mmHg}$ is necessary to treat a venous edema or ulceration. Therefore, patients capable of applying the wrap to themselves with an average pressure of more than $30 \mathrm{mmHg}$ could manage their disease on their own without the daily presence of a nurse.

On the other hand, these pathologies affect more frequently older subjects that have associated pathologies or limiting factors that can prevent an effective self-application of wraps. These restrictions have never been accurately studied in the literature. The purpose of this trial was to investigate what factors could prevent reaching a pressure of $30 \mathrm{mmHg}$ in the elderly patient's self-application of the wrap.

To do this, a private nurse asked subjects over 65 years old requiring routine nursing care to put a wrap on themselves after a demonstration.

\section{MAIN OBJECTIVE OF THE STUDY:}

- To determine the main factors that limit the self-management of an adjustable compression wrap (Circaid Juxtalite ${ }^{R}$ ) on the lower limb in subjects over 65 years of age by comparing the interface pressures recorded below the wrap in a series of patients

\section{MATERIALS :}

\section{Material}

In the absence of published data, the sample size was determined pragmatically. The 30 first retired subjects over 65 years of age seen at home the second week of November 2019 by a private nurse were included. Her coming was justified by routine nursing care (help with the toilet, injections, taking medication ...). Information was given to all study subjects before the trial. It was carried out in accordance with the WMA Helsinki Declaration.

Table I Characteristics of the population

\begin{tabular}{|c|c|c|c|}
\hline & Total & Males & Females \\
\hline Subjects (N) & 30 & 11 & 19 \\
\hline Age* (years) & $75.4(7.2)$ & $74.7(7.2)$ & $76(7.6)$ \\
\hline Weight* (kg) & $73.2(12.6)$ & $83.3(9.8)$ & $66.6(8.3)$ \\
\hline
\end{tabular}




\begin{tabular}{|l|l|l|l|}
\hline Size $^{*}(\mathrm{~cm})$ & $165(8.6)$ & $174(6)$ & $160.2(5.9)$ \\
\hline $\mathrm{BMI}^{*}\left(\mathrm{w} / \mathrm{s}^{2)}\right.$ & $26.9(4)$ & $27.6(5.3)$ & $26(3.5)$ \\
\hline
\end{tabular}

* mean (standard deviation)

Table II Main risk factors for self management ( $\mathrm{N}=30$ subjects)

\begin{tabular}{|l|c|c|c|c|}
\hline & Total N (\%) & Men & Women & Chi2 Pearson \\
\hline Obesity (BMI > 30) & $6(20 \%)$ & $3(10 \%)$ & $3(10 \%)$ & NS \\
\hline Low social level & $6(20 \%)$ & $0(0 \%)$ & $6(20 \%)$ & .002 \\
\hline Gripping difficulties & $9(30 \%)$ & $1(3.3 \%)$ & $8(26.6 \%)$ & .001 \\
\hline Cognitive disorders & $7(23 \%)$ & $2(6.6 \%)$ & $5(16.6 \%)$ & NS \\
\hline
\end{tabular}

The inclusion criteria were:

- Patients over 65 years of age;

- Retired patients;

- Patients with a CEAP classification C0-C3 (stasis edema);

- Patients followed by a private nurse for routine nursing care.

The criteria for non-inclusion were:

- Age < 65 years,

- Patients with a CEAP classification C4-C6;

- Exudative skin lesions or ulcerations;

- Lymphoedema;

- Cardiac failure;

- Neurological disorders;

- Refusal to participate to the tests;

- Persons under guardianship;

- Pedal distal pulses not perceived.

\section{Methods}

Prospective cohort study with a randomization of leg tested.

The choice of leg to apply the wrap (Figure1 Mediven Juxtalite ${ }^{R}$ ) was randomly selected from a randomization list (http://www. random. org/lists/). Pressure measurements were taken at the point $\mathrm{B} 1$ with a Kikuhime ${ }^{\mathrm{R}}$ pressure measuring device (TTmeditrade) with a $2 \mathrm{~cm}$ diameter sensor in a sitting position. The point B1 is a small area located on the leg just at the junction where the Achille's tendon joins the medial gastrocnemius muscle.

The nurse experienced in laying a wrap has demonstrated how to apply the wrap on the leg in order to reach a pressure of $40 \mathrm{mmHg}$ at the point B1 (serie 1). Immediately afterwards, the nurse asked the subject to apply the wrap twice in a row (series 2 and 3), asking him/her to try to memorize the feeling of pressure on the leg. The obtained pressures were recorded. The day after, the subject repeated the application of the wrap twice (series 4 and 5) and the pressures were also recorded. 


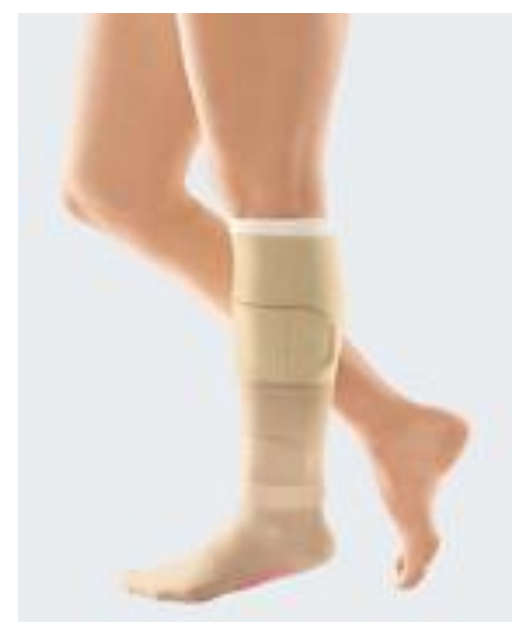

Figure1 Mediven Juxtalite ${ }^{R}$

\section{Parameters assessed during the study}

The following parameters were assessed, according our experience in the absence of published data:

. Interface pressure measured at the point B1 in sitting position. If the pressure obtained was higher than $30 \mathrm{mmHg}$, we considered that the wrap had been laid correctly.

. Sex, age, weight, height, body mass index (BMI)

. Cognitive functions were evaluated using the clock-drawing test (15). It is a simple tool that is used to screen people for signs of neurological problems, such as Alzheimer's and other dementias. The subject has to draw the numbers and hands of the clock, indicating the time of 11h 10. The nurse estimated that a subject who was unable to draw the clock correctly had a cognitive function disorder, regardless of the level of severity.

. Gripping difficulties: when the patient complained of more or less intense pain in the thumb when stretching the wrap with or without the existence of deformities in the hand.

. Criteria for low social level: patient with free care. In France, a patient with low level of resources does not pay for medical care, medicines and nursing care.

We did not have subjects lost to follow-up.

\section{STATISTICAL ANALYSIS :}

We used the JMP software (mac version 3.0)

We compared the interface pressure according to the different parameters and risk factors by using a mean comparison ( $t$ test of Student).

Chi2 exact test of Fischer was used to compare 2 groups of patients (average interface pressure $>$ or $=30 \mathrm{~mm} \mathrm{Hg}$ and $<30 \mathrm{~mm} \mathrm{Hg}$ ) according to the risk factors.

\section{RESULTS :}

We did not observe any difference in pressure between adjustable compression wraps applied to left or right legs and between left or right-handed people. 
For each patient, we first compared the pressures obtained during the 4 series of wrap application (mean comparison, Student's $t$ test). We found no significant variation of pressure from one application to another between the different sessions and one day to another.

But we found highly significant difference between pressure obtained after the nurse's demonstration and the mean pressures measured after the subjects applications. (table III).

So, we further decided to use the mean pressures obtained during the 4 series of applications for each subject.

Table III: Interface pressure assessed during the different series

\begin{tabular}{|l|l|l|l|l|l|l|}
\hline $\begin{array}{l}\text { Pressures in } \\
\text { mmHg }\end{array}$ & $\begin{array}{l}\text { Nurse's } \\
\text { demonstration }\end{array}$ & $\begin{array}{l}\text { Patients } \\
\text { Series 2 }\end{array}$ & $\begin{array}{l}\text { Patients } \\
\text { Series 3 }\end{array}$ & $\begin{array}{l}\text { Patients } \\
\text { Series 4 }\end{array}$ & $\begin{array}{l}\text { Patients } \\
\text { Series 5 }\end{array}$ & Series mean \\
\hline Mean (SD) & $39.5(2)^{*}$ & $23(8)$ & $25.4(10)$ & $22(8)$ & $25(8.8)$ & $23.8(8.8)^{*}$ \\
\hline Median & 39 & 24 & 24.5 & 21.5 & 26.5 & 24 \\
\hline
\end{tabular}

All mean comparison between the patients' series were NS

* Between nurse and patient's mean pressure $\mathrm{p}<.01$

We then compared the mean interface pressure according to the risk factors (table IV).

We found a significative decrease of pressure with the following factors:

. Obesity (BMI>30);

. Gripping difficulties;

. Low social level;

. And cognitive disorders.

The role of age ( $<75 \mathrm{vs}>75)$ was not significant.

We also compared the difference of pressure according to the associated pathologies or limiting factors between the overall study population and the subgroup with the associated pathology. Obesity, gripping difficulties, cognitive disorders and low social status appear as factors limiting the self-use of an adjustable compression wrap in the elderly (table IV).

Table IV: Comparison of the mean interface pressure according to the factors limiting selfmanagement.

\begin{tabular}{|c|c|c|c|}
\hline Interface pressure & Mean & Standard deviation & $\begin{array}{c}\text { Student's t } \\
\text { test }\end{array}$ \\
\hline Overall population $\mathrm{n}=30$ & 23.8 & 8.8 & \\
\hline Age $>75 \mathrm{n}=14$ & 22.57 & 8.0 & $\mathrm{~ns}$ \\
\hline Obesity $\mathrm{n}=6$ & 16.1 & 4.7 & .001 \\
\hline Gripping difficulties $\mathrm{n}=9$ & 18.2 & 6.5 & .003 \\
\hline
\end{tabular}




\begin{tabular}{|c|c|c|c|}
\hline Cognitive disorders $\mathrm{n}=7$ & 18.1 & 8.5 & .003 \\
\hline Low social level $\mathrm{n}=6$ & 18.3 & 4.7 & .007 \\
\hline
\end{tabular}

Another way to study the risk factors was to compare them among two groups of patients, a group with pressures $>30 \mathrm{mmHg}$ and a group with pressures $<30 \mathrm{mmHg}$ (table V). Thirty $\mathrm{mmHg}$ is the pressure considered to be effective in healing an ulcerated wound (12) or reducing venous or even lymphatic edema.

We found a significant difference of interface pressure $(33.2 \mathrm{mmHg}$ vs $19.7 \mathrm{mmHg})$ and only $30 \%$ of the subjects were able to apply alone the device with a pressure $>30 \mathrm{mmHg}$.

Similarly, the standard deviation in the group with pressure $>30 \mathrm{mmHg}$ is small $(+/-2.4$ $\mathrm{mmHg}$ ) while in the group with pressure $<30 \mathrm{mmHg}$, the standard deviation is large $(+/-6.2$ $\mathrm{mmHg}$ ). This difference is a reflection of the quality of the laying in the group with a pressure $>30 \mathrm{mmHg}$.

Regarding the factors preventing self-use of wrap, we found a significantly higher rate of obesity, low social level, gripping difficulties and cognitive disorders in the group with a pressure $<30 \mathrm{mmHg}$. The age and the sex ratio were not found significant (table $\mathrm{V}$ ).

Table V: Comparison of 2 groups of pressure $>30 \mathrm{mmHg}$ and $<30 \mathrm{mmHg}$

\begin{tabular}{|c|c|c|c|}
\hline & Pressures $>30 \mathrm{mmHg}$ & Pressures <30 mmHg & Student's t test \\
\hline Mean pressure in mmHg & $33.6(2.4)$ & $20.5(6.2)$ & .0001 \\
\hline Number & $8(30 \%)$ & $22(70 \%)$ & - \\
\hline Age in years (SD) & $72.5(6.7)$ & $74.3(6.6)$ & $\mathrm{NS}$ \\
\hline Weight in kg (SD) & $70.4(9.3)$ & $74.6(13.6)$ & $\mathrm{NS}$ \\
\hline Height in cm (SD) & $169(6.8)$ & $163(8.7)$ & .02 \\
\hline Sex ratio females vs males & 0.6 & 0.57 & $\mathrm{NS}$ \\
\hline Risk factors & & & Chi2 Fisher \\
\hline BMI w/t ${ }^{2}(\mathrm{SD})$ & $24.4(2.4)$ & $27.8(4.0)$ & .01 \\
\hline Obesity & $0 / 6$ & $6 / 6(100 \%)$ & .003 \\
\hline Low social level & $0 / 6$ & $6 / 6(100 \%)$ & .003 \\
\hline Gripping difficulties & $0 / 9$ & $9 / 9(100 \%)$ & .001 \\
\hline Cognitive disorders & $1 / 7$ & $6 / 7(86 \%)$ & .001 \\
\hline
\end{tabular}

If we then compare the pressures of the group with less than 2 factors preventing selfmanagement to the group with 2 or more factors. We note a very significant decrease in pressure in the second group, highlighting the importance of the factors limiting the correct use of the wrap. (table VI)

Table VI: Pressures with and without factors preventing self-management

\begin{tabular}{|c|c|c|c|}
\hline $\begin{array}{c}\text { Interface pressure } \\
(\mathrm{mmHg})\end{array}$ & $\begin{array}{c}\text { Group with less than 2 factors } \\
\text { preventing self-management }\end{array}$ & $\begin{array}{c}\text { Group with more than 2 factors } \\
\text { preventing the self-management }\end{array}$ & $\mathrm{p}$ \\
\hline $\mathrm{N}$ & 14 & 16 & $\mathrm{NS}$ \\
\hline Mean & 28.8 & 18.5 & .0001 \\
\hline
\end{tabular}




\section{DISCUSSION :}

This study has some limitations:

Of course, the study sample is different from the population in which wraps are usually indicated. Our sample included more than $50 \%$ of stasis edemas, which are very common in these elderly patients with low mobility. The pragmatic nature of the study did not allow us to quantify the volume.

But the objective of this study is to evaluate the risk factors of non compliance in the elderly and we think it is obvious that in case of trophic disorders or venous ulcers, this will considerably increase the difficulty to put the wrap on. Our conclusions will therefore be equally valid in all indications of the wrap.

Due to the relative size of the sample, it is not possible to calculate the relative risk of each limiting factor. However, this study validates the selected factors limiting the daily selfmanagement of a wrap by a patient. It provides qualitative evidence of the role of the factors studied. For this reason, this pragmatic monocentric study should be considered as a pilot study.

The results of this cohort study highlights factors that limit the self-management of adjustable compression wrap in the elderly.

These factors make good clinical sense:

. Gripping difficulties. The force required to stretch the Velcro of the wrap triggers pain in the thumb in the subject with grip problems. This disability is a limiting factor in using this device. Rhizarthrosis is a cause of gripping difficulties particularly more common among older women as shown on table II.

- Cognitive disorders. The clock drawing test is a widely used cognitive screening for memory, abstract thinking, planning, motor execution. An abnormality to this test is a limitation to the understanding and to the execution of the correct application of the wrap.

. Obesity. The abdominal fat apron limits trunk flexion, especially in the elderly, and thus prevents self-application of the wrap.

. And low social status. This is a particular limiting factor. The free presence of a nurse at home every day is often the only human contact for these persons. This presence induces dependence on the nursing staff and emotional regression. These patients cultivate this dependence in order to avoid isolation. Failure to pass this test is simply a translation of this. Paradoxically, age alone is not a significant limiting factor. It all depends on the associated pathologies.

When we consider the factors limiting the self-use of wraps, we see that the same factors limit the self-use of stockings or bandages. Obesity prevents you from putting your foot on the opposite knee. Gripping difficulties and cognitive disorders represent the same obstacle.

A multi-center study including a large number of patients is possible to support these preliminary results. It would allow the relative risk of each limiting factor to be calculated. It would also identify other potential factors or correlations limiting self-management in the elderly.

Finally, the difficulties encountered in applying a compressive device to oneself should trigger a global reflection to improve compliance in the elderly. It is likely that progress will come more from wraps than from compression stockings and bandages.

\section{CONCLUSION :}


Despite its limitations (patients without trophic disorders and venous ulcers, sample size, cohort study), this study identified the main factors preventing the self-application of the device (Circaid Juxtalite ${ }^{\mathrm{R}}$ ) to the lower limb in the elderly. Only 30\% of the subjects were able to apply the wrap with an average pressure of at least $30 \mathrm{mmHg}$. Age is not a limiting factor. Obesity, gripping difficulties, cognitive impairment and low social status seem to be factors limiting the daily self-management of an adjustable compression wrap in subjects over 65 years of age.

\section{REFERENCES :}

1. Guex JJ, Mariani F, Maleti O, Hamel-Desnos C, Vasdekis S, Staelens I, Urbanek T, Traber J, Vuylsteke M, Klitfod L, Mansilha A. European training requirements in phlebology. Int Angiol. 2019 Oct;38(5):345-364.

2. Nicolaides A, Kakkos S, Baekgaard N, Comerota A, de Maeseneer M, Eklof B, Giannoukas A, Lugli M, Maleti O, Mansilha A, Myers KA, Nelzén O, Partsch H, Perrin M. Management of chronic venous disorders of the lower limbs. Guidelines According to Scientific Evidence. Part II. Int Angiol. 2020 Jun;39(3):175-240

3. Blecken SR, Villavicencio JL, Kao TC. Comparison of elastic versus nonelastic compression in bilateral venous ulcers: a randomized trial. J Vasc Surg. 2005 Dec; 42(6):1150-5

4. G Mosti, S Mancini, S Bruni, S Serantoni et al. Adjustable compression wrap devices are cheaper and more effective than inelastic bandages for venous leg ulcer healing. A Multicentric Italian Randomized Clinical Experience. Phlebology 2020 Mar;35(2):124-133.

5. PW Stather, C Petty, AQ Howard. Review of adjustable velcro wrap devices for venous ulceration Int Wound J. 2019 Aug;16(4):903-908

6. Mosti G, Cavezzi A, Partsch H, Urso S, Campana F. Adjustable Velcro Compression Devices are More Effective than Inelastic Bandages in Reducing Venous Edema in the Initial Treatment Phase: A Randomized Controlled Trial Eur J Vasc Endovasc Surg. 2015 Sep;50(3):368-74

7. Benigni JP, Uhl JF, Balet F, Filori P, Chahim M. Evaluation of three different devices to reduce stasis edema in poorly mobile nursing home patients. Int.Angiol. 2018 Aug;37(4):322-326.

8. Damstra RJ, Partsch H. Randomized, controlled trial comparing the effectiveness of adjustable compression Velcro wraps versus inelastic multicomponent compression bandages in the initial treatment of leg lymphedema. J Vasc Surg Venous Lymphat Disord. 2013 Jan;1(1):13-19.

9. Pujol-Blaya V, Salinas-Huertas S, Catasús ML, Pascual T, Belmonte R. Effectiveness of a precast adjustable compression system compared to multilayered compression bandages in the treatment of breast cancer-related lymphoedema: a randomized, single-blind clinical trial. Clin Rehabil. 2019 Apr;33(4):631-641 
10. S. Mestre, C Calais , G. Gaillard, M. Nou, M. Pasqualini, C. Ben Amor, I. Quere Interest of an auto-adjustable nighttime compression sleeve (Mobiderm ${ }^{\circledR}$ Autofit) in maintenance phase of upper limb lymphedema: the MARILYN pilot RCT Support Care Cancer. 2017; 25(8): 2455-2462

11. Kerstin Protz, Stefanie Reich-Schupke, Matthias Augustin, Kristina Hagenström Comparison of handling, pressure and wearing comfort of different compression devices for decongestion therapy Veins and Lymphatics 2018; volume 7: 7989

12. Mosti G. Partsch H. Self-management by firm, non-elastic adjustable compression wrap device Veins and Lymphatics 2017; volume 6: 7003

13. Partsch H. Reliable self-application of short stretch leg compression : Pressure measurements under self-applied, adjustable compression wraps Phlebology 2019 Apr;34(3):208-213.

14. Rabe E, Partsch H, Hafner J, Lattimer C, Mosti G et al Venous and lymphatic disorders: An evidence-based consensus statement. Phlebology 2019 Apr;34(3):208-213.

15. Kenneth I Shulman Clock- drawing: is it the ideal cognitive screening test? Int J Geriatr Psychiatry 2000 Jun;15(6):548-61.

\section{Authors' contribution}

Florence Balet collected data from elderly subjects seen during one week of care. Jean-Patrick Benigni designed and wrote the protocol and reviewed the data. Jean-François Uhl carried out the statistical analysis.

JP Benigni, JF Uhl and Maxime Chahim participated in the writing of the article. Pascal Filori read the article again.

All authors read and approved the final version of the manuscript. 